\title{
Comparison of hemorrhoidectomy combined with lis and open hemorrhoidectomy.
}

1. MCPS, FCPS (Surg)

Assistant Professor Surgery

Rawalpindi Medical University.

2. FCPS (Surg)

Associate Professor Surgery

Rawalpindi Medical University.

Correspondence Address:

Dr. Sajid Rashid

Department of surgery

Rawalpindi Medical University.

surgeondrsajidrashid@gmail.com

Article received on:

$17 / 02 / 2020$

Accepted for publication:

$13 / 04 / 2020$

\begin{abstract}
Sajid Rashid ${ }^{1}$, Naveed Malik ${ }^{2}$
ABSTRACT... Objectives: To measure the effectiveness of addition of LIS with open haemorrhoidectomy in reducing post-operative pain. Study Design: Experimental study. Setting: Surgical Unit of DHQ Teaching Hospital Rawalpindi. Period: Jan-2016 to Nov-2017. Material \& Methods: This study was conducted on total number of 60 patients $(n=60)$ with $4^{\text {th }}$ degree haemorrhoids. Patients were divided into two equal groups of 30 . In group 1 open haemorrhoidectomy with LIS was done and group 2 open haemorrhoidectomy without LIS was done. Results: Mean pain score of 2.53 with SD of 0.681 was found in group 1 (open haemorrhoidectomy with LIS) as compared to mean pain score of 7.07 with SD of 1.112 in group 2 (open haemorrhoidectomy without LIS). P-value was 0.05. T-Test was applied and difference between the two groups was found statistically significant. Conclusion: Open haemorrhoidectomy with LIS reduces post-operative pain in patients.
\end{abstract}

Key words: Lateral Internal Sphincterotomy, Open Haemorrhoidectomy, Post-Operative Pain.

Article Citation: Rashid S, Malik N. Comparison of hemorrhoidectomy combined with LIS and open hemorrhoidectomy. Professional Med J 2020; 27(11):2305-2308. https://doi.org/10.29309/TPMJ/2020.27.11.4580

\section{INTRODUCTION}

Pain is a common and most disturbing complication after hemorrhoidectomy. Number of techniques ${ }^{1}$ have been devised to reduce post operative pain. Lateral internal sphincterotomy is one good technique. It reduces pain by reducing spasm of internal anal sphincter which is the main cause of pain. ${ }^{2,3}$ Initially anal dilatation ${ }^{4,5}$ was described by lords to overcome this spasm $^{6}$ but un-intentional over-damage to internal sphincter leading to faecal incontinence limited its use especially in older patients. ${ }^{7}$

Many other ways to reduce spasm of sphincter to minimize post operative pain have been described e.g. Topical use of calcium channel blockers ${ }^{8,9}$ nitroglycerine ${ }^{10,11}$ and botulinum toxin. ${ }^{12}$

Butallthesemethods of chemical sphincterotomy ${ }^{13}$ have their limitations due to their side effects e.g headache, local inflammation, difficulty of local application of cream.

The main aim of this study was to see the effec- tiveness of lateral internal sphincterotomy when combined with open haemorrhoidectomy ${ }^{14,15,16}$ in reducing post operative pain.

\section{MATERIAL \& METHODS}

Among patients with 4th degree hemorrhoids reporting to surgical unit, DHQ hospital between Jan-2016 to Nov-2017, 60 were included in this experimental study. Both patients over the age of 55 years and patients with other pathologies like fistula, fissure were not included in the study. Patients were randomized into two groups by lottery method. Written informed consent was taken from patients. In study group 1 classical Milligan Morgan hemorrhoidectomy with LIS was done. In control group 2 milligan Morgan hemorrhoidectomy without lateral internal sphincterotomy was performed. All the patients were operated in lithotomy position under spinal anaesthesia by the same surgeon. Operation was performed with the help of diathermy to secure good hemostasis and at the end of operation in group 1 lateral internal sphincterotomy was done. Lower portion of the lateral internal sphincter upto 
the dentate line was cut through the open wound of hemorrhoidectomy on left side. Gause Pack with pyodine and lignocaine gel was placed in anal canal and $T$ bandage applied. On first post operative day the anal pack was removed and sitz bath in warm water with pyodine was started. All the patients were given third generation cephalosporin and flagyl infusion, one doze pre operatively and two dozes postoperatively.

Postoperative pain was monitored by surgeon unaware of the groups by visual pain scale. Injection tramadol hydrochloride was used as analgesic. Pain score was noted three times a day and recorded for each patient. Monitoring was done for 3 days postoperatively then average pain score for each patient was calculated. Patients were discharged on 4th postoperative day and were called for follow up on 7th post operative day to see for any complication like fecal incontinence. Examination was done carefully on follow up by the operating surgeon to record the findings. Then these patients were followed once a month for 6 months to see for long term complications e.g. anal stenosis and long lasting pain. All the data was recorded on a pre-designed Performa. P-Value was set at 0.05 . T- Test was used to see statistical significance. Data was analysed by SPSS 20 program.

\section{RESULTS}

Experimental study was conducted on 60 patients $(n=60)$ divided in two groups with 30 patients in each. P-value was 0.05 . data analysis was done by SPSS 20. In group 1 (open haemorrhoidectomy with LIS) mean age of patients was $42.50 \mathrm{y}$ and in group 2 (open haemorrhoidectomy without LIS) mean age of patients was $42.90 \mathrm{y}$. Mean pain score in group 1 was 2.53 with SD of 0.681 where as in group 2 mean pain score was 7.07 with SD of 1.112. T-Test was applied and difference between two groups was found statistically. In group 1 only one patient developed incontinence for flatus in early post operative period and it settled during next 06 weeks.

\begin{tabular}{|c|c|c|c|c|c|}
\hline & $\mathbf{N}$ & \multicolumn{2}{|c|}{ Minimum } & Maximum & Mean \\
\hline Age in Years & 30 & \multicolumn{2}{|c|}{30} & 57 & 42.50 \\
\hline Valid N (listwise) & 30 & & & & \\
\hline \multicolumn{6}{|c|}{ Group-I. Open haemorrhoidectomy with LIS } \\
\hline & $\mathbf{N}$ & \multicolumn{2}{|c|}{ Minimum } & Maximum & Mean \\
\hline Age in Years & 30 & \multicolumn{2}{|c|}{32} & 57 & 42.90 \\
\hline Valid N (listwise) & 30 & & & & \\
\hline \multicolumn{6}{|c|}{ Group-II. Open haemorrhoidectomy without LIS } \\
\hline $\begin{array}{c}\text { Visual } \\
\text { Pain Scale } \\
\text { Scale(0-10) }\end{array}$ & $\mathbf{N}$ & Min & Max & Mean & S.D \\
\hline Valid N & 30 & 1 & 4 & 2.53 & 0.681 \\
\hline \multicolumn{6}{|c|}{$\begin{array}{l}\text { Group-I. Mean pain score in open } \\
\text { haemorrhoidectomy with LIS }\end{array}$} \\
\hline $\begin{array}{c}\text { Visual Pain } \\
\text { Scale Scale } \\
(0-10)\end{array}$ & $\mathbf{N}$ & Min & Max & Mean & S.D \\
\hline Valid N & 30 & 5 & 9 & 7.07 & 1.112 \\
\hline $\begin{array}{r}\text { Grou } \\
\text { hae }\end{array}$ & II. $N$ & $\begin{array}{l}\text { In pai } \\
\text { lector }\end{array}$ & core & $\begin{array}{l}\text { open } \\
\text { LIS }\end{array}$ & \\
\hline
\end{tabular}

\section{DISCUSSION}

In Pakistani community haemorrhoidal bleeding is a common problem in middle age group of both males and females. There are many surgical procedures to treat hamemorrhoids ${ }^{17}$ but in our country open milligan-morgan haemorrhoidectomy is mostly used. ${ }^{18,19,20}$ Whatever the surgical procedure is used pain is the most common complication. ${ }^{21}$

Lateral internal sphincterotomy through the haemorrhoidectomy wound relaxes the muscle and reduces its tone hence reduces pain as seen in our study. 22,23,24 Different studies show effectiveness of LIS when combined with haemorrhoidectomy. M.W Raza et al ${ }^{25}$ confirmed the effectiveness of LIS with haemorrhoidectomy. Similarly DK Das et $a^{26}$ gave same result in his study with minimal complications.

Amoroti ${ }^{27}$ conducted study and combined LIS with milligan morgan haemorrhoidectomy and gave good results regarding post operative patient comfort. Same is the result of study conducted by Mukadum \& Masu. ${ }^{28}$ 
A prospective was conducted by Kenlos $\left.\right|^{29}$ and he found that combination of LIS with haemorrhoidectomy significantly reduces post operative pain of the patients. Contrary to the results shown by the above mentioned studies which confirm the results of this study, Khubchandani $\mathrm{IT}^{30}$ showed in his study that adding LIS to haemorrhoidectomy has no effect on post operative pain. He also reported increased incidence of feacal incontinence ${ }^{31}$ in his patients. However our study confirms the results of the studies showing benefits of open haemorrhoidectomy with LIS with minimal complications.

\section{CONCLUSION}

Milligan morgan haemorrhoidectomy with LIS is an effective method of significantly reducing post operative pain without any complications.

\section{Copyright $(13$ Apr, 2020.}

\section{REFERENCES}

1. T. Higuero, L. Abramowitz, A. Castinel, N. Fathallah, P. Hemery, C. Laclotte Duhoux, F. Pigot, H. Pillant-Le Moult, A. Senéjoux, L. Siproudhis, G. Staumont, J.M. Suduca and B. Vinson-Bonnet, Guidelines for the treatment of hemorrhoids (short report), Journal of Visceral Surgery. 2016; 153(3):213.

2. Pescatori, M, Favetta, $U$, Navarra, $L$ Anal pressures after hemorrhoidectomy Int. J. Colorectal Dis.1998; 10(4):131-49.

3. Ma-Mu-Ti-Jiang A ba-bai-ke-re, Hong-Guo Huang,Wen$\mathrm{Ni} \mathrm{Re}$, Kai Fan, Hui Chu, Er-Ha- Ti-Ai, Mai-Mai-Ti-Tu-ErXun KE Li-Mu, Yi-Rui Wang and Hao Wen. How can we improve patients' comfort after Milligan- Morgan open haemorrhoidectomy? World J Gastroenterol. 2011; 17(11):1448-56.

4. Mortensen PE, Olsen J, Pedersen IK, Christiansen J. A randomized study on hemorrhoidectomy combined with anal canal dilatation. Dis. Colon Rectum. 1987; 19: 755-757.

5. Lord PH. Digital dilatation for hemorrhoids treatment. Int Surg. 1989; 74: 144-145.

6. Champigneulle B, Dieterling P, Bigard MA, Gaucher $P$. Prospective study of the function of the anal sphincter before and after hemorrhoidectomy. Gastroenterologie clinique et biologique. 1989 May;13(5):452.
7. Asfar SK, Juma TH, Ala-Edeen T. Hemorrhoidectomy and sphincterotomy. A prospective study comparing the effectiveness of anal stretch and sphincterotomy in reducing pain after hemorrhoidectomy. Dis. Colon Rectum. 1988; 31: 181-185.

8. Suchdev S, Ghayassuddin M, Younus SM,Mirani AJ, Ghias N, Qazi A, et al. Calcium Channel Blockers for pain relief after haemorrhoidectomy; A randomized controlled from Karachi Pakistan. Pak J Surg. 2014; 30(2):187-92.

9. H. A. Amoli, A. Y. Notash, F. J. Shahandashti, A. Y. Kenari and $\mathrm{H}$. Ashraf, A randomized, prospective, double-blind, placebo-controlled trial of the effect of topical diltiazem on post haemorrhoidectomy pain, Colorectal Disease. 2011; 13(3):328-332.

10. Wasvary HJ, Hain J, Mosed-Vogel, M.et al. Randomized, Prospective, double-blind placebo controlled trial of effects of nitroglycerine ointment on pain after hemorrhoidectomy. Dis. Colon Rectum. 2001; 44:106973.

11. Muhammad Rafay Sameem Siddiqui, Chuk AbrahamIgwe, Arun Shangumanandan, Veronica Grassi, Ian Swift and Al Mutaz Abulafi, A literature review on the role of chemical sphincterotomy after MilliganMorgan hemorrhoidectomy, International Journal of Colorectal Disease. 2011; 26 (6): 685.

12. Davies J, Duffy D, Boyt N, Aghahoseini A, Alexander $D$, Leveson $S$. Botulinum toxin (botox) reduces pain after hemorrhoidectomy: Results of a double-blind, randomized study. Dis Colon Rectum. 2003; 46:10971102.

13. Ho YH, Seow-Choen F, Low JY, Tan M, Leong AP. Randomized controlled trial of trimebutine (anal sphincter relaxant) for pain after haemorrhoidectomy. British Journal of surgery. 1997 Mar;84(3):377-9.

14. Di Bella F, Esteinne G. Indications for internal medioposterior lateral sphincterectomy with anoplasty during hemorrhoidectomy. Our experience. Minerva-Chir. 1990; 45(6):361-63.

15. Sameh Hany Emile, Mohamed Youssef, Hossam Elfeki, Waleed Thabet, Tito M. Abd El-Hamed and Mohamed Farid, Literature review of the role of lateral internal sphincterotomy (LIS) when combined with excisional hemorrhoidectomy, International Journal of Colorectal Disease.2016;31, 7, 1261. 
16. Ioannis Kanellos, Emmanouil Zacharakis, Emmanouil Christoforidis, Stamatis Angelopoulos, Dimitrios Kanellos, Manousos Georgios Pramateftakis and Dimitrios Betsis, Usefulness of lateral internal sphincterotomy in reducing postoperative pain after open hemorrhoidectomy. World Journal of Surgery. 2005 10.1007/s00268-004-7432-2, 29, 4, (464-468).

17. Martin Luchtefeld and Rebecca E. Hoedema. Hemorrhoids: The ASCRS Textbook of Colon and Rectal Surgery; 2016; 259-70. 183-203.

18. Mathai V, Ong BC, Ho YH. Randomized controlled trial of lateral internal sphincterotomy with haemorrhoidectomy. Br J Surg. 1996; 83: 380-382.

19. Schouten WR, van Vroonhoven TJ. Lateral internal sphincterotomy in the treatment of hemorrhoids. Dis. Colon Rectum. 1986; 29: 869-872.

20. Leong AF, Husain MJ, Seow-Choen F, Goh Hs. Performing internal sphincterotomy with other anorectal procedures. Dis. Colon Rectum. 1994; 37 : 1130-1132.

21. Sameh Hany Emile, Evidence-based review of methods used to reduce pain after excisional hemorrhoidectomy, Journal of Coloproctology, 2018; 10(1016):10.007.

22. Safwan AT. Routine internal sphincterotomy with the hemorrhoidectomy for third and fourth degree hemorrhoids greatly improves the outcome. IJGE. 2003; 4(1):48-51.

23. Eisenhammer S. Internal anal sphincterotomy plus free dilatation versus anal stretch procedure for hemorrhoids. Dis Colon Rectum 1974; 17(4):493-522.

24. Seyed Vahid Hosseini, Khosro Sharifi, Azadeh Ahmadfard, Mahnaz Mosallaei, Saeideh Pourahmad, Shahram Bolandparvaz. Role of Internal Sphincterotomy in the Treatment of Hemorrhoids: A Randomized Clinical Trial. Arch Iranian Med. 2007; 10(4): 504-508.
25. Raza MW, Khan A, Kamran RA, Waqas K, Yusuf A. Haemorrhoidectomy with or without lateral internal sphincterotomy. JRMC. 2013; 17(2):189-91.

26. Das DK, Choudhury UC, Lim ZS. Effectiveness of internal sphincterotomy in reducing post hemorrhoidal pain: A randomized comparative clinical study. International journal of collaborative research on internal medicine \& public health 2013; 5(6):428-35.

27. Amorotti C, Mosca D, Trenti C, Pintaudi U. Usefulness of lateral internal sphincterotomy combined with hemorrhoidectomy by the Milligan-Morgan's technique: Results of a prospective randomized trial. Chir Ital. 2003; 55 (6): 879-86.

28. Mukadam P, Masu S. Internal sphincterotomy as a postoperative pain relieving method in patients operated for open hemorrhoidectomy. J Res Med Den Sci. 2014; 2(1):55-58.

29. Kanellos I, Zacharakis E, Christoforidis E, Angelopoulos S, Kanellos D, Pramateftakis MG, et al. Usefulness of lateral internal sphincterotomy in reducing postoperative pain after open hemorrhoidectomy. World J. Surg. 2005; 29(4):464-68.

30. Khubchandani IT. Internal sphincterotomy with hemorrhoidectomy does not relieve pain: $A$ prospective randomized study. Dis. Colon Rectum. 2002; 45(11):1452-57.

31. Rotholtz NA, Bun M, Mauri MV, Bosio R, Peczan CE, Mezzadri NA. Long term assessment of fecal incontinency after lateral internal sphincterotomy. Tech Coloproctol 2005; 9:115-8.

\begin{tabular}{|c|c|c|c|}
\hline \multicolumn{4}{|c|}{ AUTHORSHIP AND CONTRIBUTION DECLARATION } \\
\hline Sr. \# & Author(s) Full Name & Contribution to the paper & Author(s) Signature \\
\hline 1 & Naveed Malik & $\begin{array}{l}\text { Principal investigator, Wrote all } \\
\text { parts of article except introduction } \\
\text { and references. } \\
\text { Wrote introduction and references. } \\
\text { Took part in data collection. }\end{array}$ & 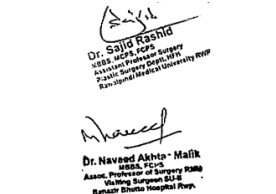 \\
\hline
\end{tabular}

